\title{
Publicidad en torno al mito: el uso de figuras mitológicas como herramienta persuasiva del discurso publicitario.
}

\author{
Alfonso Freire SÁNCHEZ \\ Universitat Abat Oliba CEU \\ freire3@uao.es
}

\section{Resumen:}

El presente artículo tiene como objeto de estudio la reproducción y repetición de numerosas figuras mitológicas clásicas en la producción publicitaria contemporánea, y está ordenado con el fin de averiguar la causa de este fenómeno y de qué manera influye en la construcción de arquetipos en la sociedad posmoderna y, a su vez, en sus tendencias consumistas, consecuentemente, posicionando a la publicidad como la mitología de nuestros días.

Palabras claves: Publicidad; mito; arquetipo; mitología clásica; marca; creatividad.

\section{Advertising around the myth: use of mythological figures as a persuasive tool of advertising discourse.}

\begin{abstract}
:
This paper attempts to study the reproduction and repetition of many classic mythological figures in contemporary advertising productions, and is sorted in order to find the cause of this phenomenon and its influence in the construction of archetypes in postmodern society as well as in consumer trends, resulting in advertising becoming today's mythology.
\end{abstract}

Key Words: Advertising; myth; archetypes; classical mythologies; brand; creativity.

\section{Referencia normalizada:}

Freire Sánchez, A. (2014): Publicidad en torno al mito: el uso de figuras mitológicas como herramienta persuasiva del discurso publicitario. Historia y Comunicación Social. Vol. 19. Núm. Especial Marzo. Págs. 241-251

Sumario: 1. Introducción: discurso publicitario y mito. 2. Metodología. 3. Elementos intangibles que construyen las marcas. 4. Una propuesta de clasificación: arquetipos modélicos y posicionamiento. 5. Conclusiones: mitemas y sueños oníricos. 6. Referencias Bibliográficas. 7. Anexo. 


\section{Introducción: discurso publicitario y mito}

Desde el punto de vista alejado del estudio y la praxis de la publicidad, el discurso publicitario puede entenderse como una herramienta puramente persuasiva con la única misión de convencer al espectador-consumidor de las "asombrosas" y "magníficas" cualidades y características de un producto o servicio y su necesaria adquisición o contratación inmediata para mejorar su calidad de vida. No obstante, aunque el fin último de la publicidad sea conseguir un importante retorno económico de las campañas publicitarias, es decir, estimular las ventas y aumentar la cuota de mercado y el valor de marca, no podemos obviar que la publicidad es una actividad eminentemente comunicativa y, en la mayoría de las ocasiones, está alejada de la frivolidad y de la casualidad, más bien al contrario, manifiesta un profundo y profeso respeto por el consumidor y por las reglas de mercado. Del mismo modo, la publicidad es, en esencia, un arte o, más sucintamente, un compendio de artes: retórica, lírica, poética y composiciones narrativas audiovisuales provistas de estética y armonía, acompañadas del arte musical e interpretaciones artísticas. Todo ello produciendo un complejo discurso que, como dice Adrián Huici (1993: 73), "es una de las actividades esenciales al hombre."

El discurso humano y, por consiguiente, el discurso publicitario de nuestra era se nutre del creciente gusto popular por el mito clásico y moderno. Su influencia no consiste en una sucesión de fenómenos culturales arbitrarios y desconectados sino en una reproducción masiva de arquetipos clásicos y modernos, estereotipos y estética mitológica muy evidente en las artes literarias y escenográficas, como la narrativa audiovisual publicitaria. Los mitos, mediante el sustrato histórico, se han magnificado como iconografías, símbolos y representaciones de gran significación y potencia visual que regeneran y cimientan el imaginario de la sociedad posmoderna, confiriendo significado y evocaciones (visibles u ocultas) al discurso publicitario y, consecuentemente, se constituyen como una herramienta clave en publicidad.

Ante tal fenómeno, la problemática que se plantea es si, en primer lugar, existe un patrón que teorice y apuntale el uso de arquetipos y figuras mitológicas como instrumento del discurso publicitario y el branding o, por el contrario, responde a producciones arbitrarias y desprovistas de una pauta correlativa de contenido teorético y pragmático. En segundo lugar, identificaremos y definiremos el rol del mito en la sociedad posmoderna para investigar acerca de los modos en que la mitología se regenera y retroalimenta mediante el discurso publicitario e influye en las tendencias consumistas.

\section{Metodología}

El presente artículo parte de la concepción del mito como parte intrínseca y constituyente del discurso publicitario, pues se comprende que la publicidad (como el 
cine) es una manifestación del pensamiento humano que se prolonga más allá del simbolismo y del significado cultural que la mitología le ha transferido. Por tanto, no partiremos de una apriorística aproximación etimológica ni a un recorrido histórico de la herencia de la mitología en la sociedad posmoderna o la conciencia mítica (Gusdorf, 1990), sino que confrontaremos el análisis de campañas con las diversas teorías que construyen este marco referencial: especulativas como son las de Carol Pearson y Margaret Mark basadas en la composición de los valores intangibles que forman la imagen de marca y en qué sentido se asocia el target con este imaginario; teorías que tratan el mito como elemento nuclear del discurso publicitario como es el caso de Adrián Huici o cuando el discurso publicitario busca la emotividad desde un registro mítico: sus relatos, representaciones, imágenes, personificaciones y símbolos se dirigen al espectador (Roland Barthes, 1982); y, de una forma más hermenéutica y analítica, aquellas que intentan analizar la publicidad desde el mito: el caso de José Luís León y su concepción del Mitoanálisis de la Publicidad, en el que, incluso, divide esta relación en tres dimensiones: literal, alegórico y reconstrucción del sentido figurado. Del propio León adoptaremos el concepto de mitema para clasificar los temas oníricos que responden a los clásicos de la mitología clásica y que se repiten en la publicidad actual: carpe diem, búsqueda de paraísos idílicos, la tentación como (León: 2001) los famosos cantos de las sirenas en referencia a La Odisea de Homero, etc.

Tanto unas como otras teorías no dejan cabida a la arbitrariedad respecto al uso de figuras y símbolos mitológicos en el discurso publicidad, bien al contrario, lo conciben como parte integral de la persuasión y construcción de los denominados brand insights. Ulteriormente, se propondrá una clasificación propia en función del mitema que reproducen algunas de las campañas más notorias del siglo XX y el arquetipo modélico en el cual se han construido y han basado su posicionamiento.

\section{Elementos intangibles que construyen las marcas}

Según David Aaker (1989: 27): "la identidad de marca es un conjunto de activos (y pasivos) vinculados al nombre y símbolo de la marca que incorporan (o sustraen) el valor suministrado por un producto o servicio a la compañía y/o sus clientes" Dentro de la identidad de marca, encontraremos valores tangibles tales como el producto, el precio, la distribución, el packaging, etc. Asimismo, hallamos valores intangibles (sean racionales o emocionales) como la calidad percibida, la asociación de significados, la notoriedad, el reconocimiento, la personalidad, la vinculación a un status social determinado, etc. El compendio de valores intangibles que conforman las marcas según la percepción común que tienen los consumidores sobre éstas se conocen como los brand insights. Los insights, como los arquetipos, forman parte del inconsciente colectivo pues son aquellas percepciones generales y comunes que tienen los consumidores respecto a las marcas y los valores que las representan, por tanto, es posible afirmar que son parte constructora de la brand equity $\mathrm{y}$, por consiguiente, elementos 
clave para que una marca se considere una lovemark: (Kevin Roberts, 2004) aquella marca que se posiciona en la mente y en el corazón del consumidor y posee un valor de marca tan excelso que consigue que los consumidores, además de pagar por el servicio o producto que ofrecen, lo hagan por el status quo que proporcionan. Las lovemarks, en gran medida, establecen cuantiosos paralelismos y similitudes con los patrones mitológicos clásicos y sus iconos son los arquetipos modélicos de la era posmoderna. Por ello, algunas de estas marcas, como Apple, Ferrari o Nike, serán las que encabezarán el presente estudio.

A diferencia de los elementos tangibles, incorporar el valor de los intangibles en cuanto a la eficacia de la publicidad resulta una tarea mucho más ardua. Se induce que la interpretación de un análisis publicitario no legitimado mediante cifras objetivas de mercado pueda quedar en entredicho y deba justificarse. No obstante, más allá de las cifras objetivas del mercado, existen otros datos -no enteramente cuantificables- como la notoriedad, el grado de repercusión, las asociaciones de marca o brand insights, los elementos visuales que caracterizan a una marca y son reconocidos por el espectador-consumidor o, dicho de otra manera, los ownables, etc., que permiten establecer un cómputo global de estos valores, como son el Brand Essence Building de Young \& Rubicam, la Brand Equity (lealtad a la marca, conciencia de pertenencia, calidad percibida, asociaciones de marca y otros activos) que propone David Aaker.

Pese a que, a priori, el término valor de marca pudiera parecer ambiguo, el conocimiento de estos es de gran importancia y utilidad para los responsables de marketing de las empresas, dado que para que las campañas publicitarias sean eficaces deben tener consonancia con los valores culturales que priman en una sociedad determinada. Por tanto, resulta lógico que los insights sean objeto de estudio por parte de los expertos en el comportamiento del consumidor, de los planners $\mathrm{y}$, en general, de los profesionales del marketing. Se ha demostrado de la asociación de elementos, valores, rasgos y características comunes que los consumidores asocian a las marcas y que representan un elemento diferenciador en el proceso de decisión de compra. Un caso muy significativo es el de algunas marcas automovilísticas, las cuales, han conseguido asociarse a una característica que los definía por encima de otras cualidades y, evidentemente, por encima de sus competidores como, por ejemplo, el caso de Volvo con la seguridad, Mercedes con el lujo y el confort, Ferrari con la velocidad, etc. En el caso de los colores, una característica muy importante en la publicidad y en la decisión de compra, muchas marcas han conseguido asociarse con un determinado color, conformando parte de su imagen corporativa y, por consiguiente, de su línea de merchandising, pues acostumbran a ser marcas que los propios consumidores pagan por promocionar: Apple y el blanco que caracteriza a su logotipo, sus productos, su website, su packaging, incluso sus concept stores; Ferrari y el rojo que siempre ha distinguido a la marca de Maranello, a sus automóviles, su línea de moda, inclusive a su hercúleo parque temático; o Heineken y el color verde que, no sólo está en su packaging y en su logotipo, también en su eslogan: "Piensa en Verde".

Siguiendo esta estela, es reseñable el hecho que algunas marcas incluso han logrado posicionarse y arraigarse de forma férrea en la mente de los consumidores logrando 
entrar en lo que en se conoce como el top of mind de su categoría o sector, es decir, ser la marca más recurrente por los consumidores cuanto estos piensan en una categoría concreta como son los casos de Red Bull con las bebidas energéticas, de Martini con los vermuts o de La Casera con las bebidas carbonatadas.

Todo este constructo de marca tiene una vinculación simbólica, cultural y un fuerte carácter alegórico respecto al mito pues, como veremos, recurre a los estereotipos de belleza fastuosa, de masculinidad y virilidad, de poder categórico, de tenacidad y astucia. No existen modelos referenciales más idóneos y arraigados al inconsciente colectivo que los arquetipos clásicos.

\section{Una propuesta de clasificación: arquetipos modélicos y posicionamiento}

C. Gustav Jung (2010: 10) definió los arquetipos como "imágenes antiguas que derivan del inconsciente colectivo." Contrariamente a los símbolos que siempre se mantienen ensamblados a un contexto que los nutre de significado, los arquetipos se manifiestan como estructuras morales universales, adquiridas o inherentes, (Vogler, 2002: 60) "emanan directamente del inconsciente colectivo". Los referentes arquetípicos del mundo occidental son dioses y héroes homéricos; se constituyen como herramientas recurrentes para remitir a los tiempos ancestrales, ejemplificar modelos y pautas de comportamiento y para persuadir mediante la evocación de los valores y virtudes que representan. El relato publicitario no es ex nihilo, no nace de la nada, no tiene la capacidad de inventarse a sí mismo, pero sí tiene la capacidad de recrear la realidad y transformarla, pues en la publicidad también desemboca el pensamiento estético y el universo de símbolos representativos del mito, en este sentido, la publicidad siempre se ha servido del imaginario arquetípico para construir sus marcas como, por ejemplo, Nike, Artemis o Ares, las cuales adoptan el nombre de dioses clásicos y parte de su simbología, incluso su significado, como leitmotiv. Es evidente que detrás de la diosa Niké (Atenea), diosa de la victoria que la marca de calzado y ropa deportiva Nike emula, existe una importante multinacional y una filosofía de marca que, probablemente, mantendrá pocos de los valores que indujeron a las civilizaciones clásicas a creer en la diosa homérica más allá del citado simbolismo (también emulado por su logotipo) de la victoria. Pero, como sucede con Nike y otras marcas, el simbolismo y los valores que heredan del mito siembran los cimientos para la construcción del resto de imagen de marca, adaptados a los tiempos posmodernos.

¿Hasta qué punto es original el relato publicitario? Heredera de las artes plásticas y literarias, coetánea del cine, la publicidad, como éste, ha transmitido y transformado los argumentos universales en cortos relatos publicitarios: la búsqueda del tesoro, Jason y los Argonautas, el retorno al hogar la Odisea, la fundación de una nueva patria, la Eneida, etc. Asimismo, se ha servido de modelos arquetípicos clásicos: dioses y héroes, y otras figuras clásicas que forman parte de la mitología antigua como quimeras y monstruosidades. Sin embargo, en la mayoría de las ocasiones, 
la publicidad no asimila o acoge llanamente el mito, pues resulta obvio que, para que éste sea fácilmente aceptado por la cultura contemporánea, debe ser adaptado, traducido a la narrativa posmoderna actual y, en definitiva, debe conformarse como un crisol cultural legible.

Esta adaptación podría clasificarse mediante los mitemas que propone León (2010), de entre los cuales, los más comunes son:

- el paraíso prometido: el edén

- el ideal de la belleza perfecta: afrodita el arquetipo de la sensualidad

- el rejuvenecimiento y la vida eterna: Perséfone, el arquetipo de la juventud

- el heroísmo: Ulises (astucia), Héctor (defensor), Aquiles (héroe por excelencia con una debilidad)

- el poder: Zeus

- la tentación: el canto de las sirenas.

- la victoria: Atenea (Niké)

- el éxito: narciso el arquetipo de autocomplacencia e individualismo

- la rebeldía contra el orden: Perseo el arquetipo de salvador; Prometeo el arquetipo de rebelde que se sacrifica por el ser humano.

- la búsqueda de un tesoro: Jason y los argonautas y la búsqueda del vellocino de oro.

- carpe diem: Dionisio, el arquetipo de la fiesta y la alegría

- la libertad: Artemisa

¿Cómo se sirven las marcas de los arquetipos? En la Revolución Creativa de los 60, destacó por encima de todos los directores creativos Bill Bernbach, sin menospreciar a otras grandes como Leo Burnett, David Ogilvy o George Lois. Parte de su legado, son sus principios sobre cómo realizar una campaña publicitaria, en concreto, el noveno: ¡Take a stand! (¡Tome una posición!), señala el inicio de lo que, posteriormente, Jack Trout, Al Ries o, el ya citado, Ogilvy, definirían como posicionamiento, un factor estratégico imprescindible para que las marcas consigan ubicarse en la mente del consumidor y tener una presencia activa en el mercado y, en algunos casos, situarse como líderes dentro de su sector.

En la década de los años 60, la marca de tabaco Marlboro era considerada una marca de cigarrillos para mujeres debido a que éstas, en su mayoría, lo elegían, pues el color ocre característico de su boquilla evitaba que se viese el residuo de los pintalabios, lo cuál era indicativo teniendo en cuenta que, la mayoría de los cigarros poseían una boquilla blanca. Marlboro ostentaba la décima cuota de mercado y, por ello, decidió contratar a Burnett para que llevase a cabo su nueva campaña publicitaria. Burnett decidió basarla en la figura del arquetipo de héroe rudo, valiente, 
solitario y, sobre todo, muy varonil, creando el que se conoció como el Cowboy de Marlboro. Este personaje representaba los valores masculinos necesarios para lograr reposicionar la marca de la tabacalera Philip Morris de tal forma que, en pocos meses, se situó como la primera marca de cigarrillos en ventas en EEUU. Sin duda alguna, es un claro ejemplo de la influencia de los arquetipos modélicos en las tendencias del consumidor, pero no se trata de un caso exclusivo, Esta figura varonil y solitaria también reúne -a grandes rasgos- los elementos del arquetipo del aventurero que siempre ha impulsado los brand insights de marcas como Harley Davidson, Camel o, la anteriormente considerada, Marlboro. El arquetipo de aventurero tiene también ciertas connotaciones nihilistas y relativistas, pues es una clara apología del carpe diem, del individualismo posmoderno y de la sobrestimulación del my self, es decir, del yo mismo.

El embarcarse en la tarea de descifrar los mensajes y códices que conforman el discurso publicitario y que provienen del legado cultural de la mitología clásica entrevé la compleja empresa de distinguir aquellos relatos que son fruto de la casualidad, arbitrariedad e incluso se podría decir, del efecto de mímesis de aquello que es causal, de aquello que forma parte del fruto del estudio de mercado, de la investigación de los valores culturales, de la planificación de complejos posicionamientos en la mente del consumidor, en el corazón del consumidor, es decir, fruto de la causalidad. Las fuentes principales se desvanecen rápidamente en teorías que nada o poco tienen que converger con el citado discurso y se encaminan más hacia el séptimo arte o a aspectos tan poco argumentados que, de alguna manera, distorsionan la percepción apriorística que uno pudiera tener sobre el tema en cuestión: (Mark; Pearson:2001). El relato publicitario se sirve de la parte verbal de la narración y de la parte visual, conformándose como una de las mayores herramientas para crear, recrear y transformar realidades, así como afirma Ricardo Yepes (1993:26): "La información visual llega directamente a la sensibilidad y a la afectividad; es mucho más penetrante que la información verbal, más cálida, más inmediata." Si bien, toda marca posee un símbolo, en muchas ocasiones estos símbolos recrean figuras de mitología animal que evocan una serie de significados y valores como, por ejemplo, el toro de Red Bull, el caballo de Ferrari o el león de Peugeot. En la parte inferior podemos ver una tabla sobre los valores de algunos de los animales mitológicos que forman parte de la iconografía publicitaria actual:

\begin{tabular}{||l|l|l||}
\hline \multicolumn{1}{|c|}{ ANIMALES } & \multicolumn{1}{|c||}{$\begin{array}{c}\text { SIGNIFICADOS Y } \\
\text { VALORES }\end{array}$} & \multicolumn{1}{||}{ MARCAS } \\
\hline CERDO & $\begin{array}{l}\text { Servicio, abundancia, } \\
\text { ahorro, utilidad, } \\
\text { redondez, rentabilidad }\end{array}$ & $\mathrm{BBV}$ \\
\hline CABALLO & $\begin{array}{l}\text { Dinamismo, energía, } \\
\text { fuerza, naturaleza en } \\
\text { bruto, libertad }\end{array}$ & Campsa \\
\hline
\end{tabular}




\begin{tabular}{||l|l|l|}
\hline OSO & $\begin{array}{l}\text { Protección, seguridad, } \\
\text { afecto, ambiente } \\
\text { familiar, complicidad, } \\
\text { suavidad, calor }\end{array}$ & Santa Lucía \\
\hline TORO & $\begin{array}{l}\text { Bravura, libertad, } \\
\text { generosidad, nobleza, } \\
\text { fuerza, vitalidad, } \\
\text { carácter }\end{array}$ & Osborne \\
\hline CORDERO & $\begin{array}{l}\text { Protección, suavidad, } \\
\text { ternura, blancura, } \\
\text { relación corporal } \\
\text { infantil, inocencia }\end{array}$ & Norit \\
\hline PERRO & $\begin{array}{l}\text { Amistad, lealtad, } \\
\text { fidelidad, ambiente } \\
\text { hogareño, libertad, } \\
\text { familiar, sencillez, } \\
\text { acogimiento }\end{array}$ & Génesis \\
\hline
\end{tabular}

Fuente: Javier Alonso/ Ildefonso Grande (2010:84)

Los mitemas, como si de los ideales del mundo supraceleste - platónico-se tratase, sólo harán partícipe de su imaginario al consumidor mediante el relato publicitario. A menudo, conforman parte de la escenografía e iconografía del propio relato, en otras ocasiones, son parte intrínseca de la imagen de marca, aunque, por lo general, acostumbran a asociarse con la denominada promesa que dichas campañas publicitarias usan de eje comunicativo para persuadir a su público objetivo. Escoger la promesa adecuada en el eje comunicativo de una campaña puede significar la diferencia entre incrementar las ventas o fracasar en el mercado. Muchos autores se han referido a la citada promesa con otros nombres o calificativos, como es el caso de John Caples (1975:34):

He comprobado que un determinado anuncio vendía en realidad no dos o tres veces más que otro, sino $19 \mathrm{y}$ 1/2 veces más. Ambos anuncios ocupaban el mismo espacio y aparecían en la misma publicación. Ambos tenían ilustraciones fotográficas y un texto cuidadosamente elaborado. La diferencia consistía en que uno utilizaba el estímulo correcto y el otro, el incorrecto.

A continuación, podemos observar una tabla que se ha realizado para el presente artículo, en la que se han clasificado algunas marcas según el mitema y el uso o tipo que se hace de ellos en sus campañas:

\begin{tabular}{|c|c|c|}
\hline MITEMA & ARQUETIPO / USO & MARCA/CAMPAÑA \\
\hline Heroísmo & $\begin{array}{l}\text { Arquetipo Guerrero } \\
\text { (Aquiles)/ Aventurero } \\
\text { (Ulises) }\end{array}$ & $\begin{array}{l}\text { Marlboro / el } \\
\text { cowboy de Marlboro } \\
\text { (reposicionamiento) }\end{array}$ \\
\hline & & $\begin{array}{l}\text { Harley Davidson } \\
\text { (construcción de marca) }\end{array}$ \\
\hline
\end{tabular}




\begin{tabular}{|l|l|l|}
\hline $\begin{array}{l}\text { Alcanzar un } \\
\text { sueño }\end{array}$ & Emocional & $\begin{array}{l}\text { Audi / Harley 1991 (de } \\
\text { publicidad racional a } \\
\text { emocional) }\end{array}$ \\
\hline Libertad & Emocional (Ícaro) & $\begin{array}{l}\text { BMW / ¿Te gusta conducir? } \\
\text { 2001 (de publicidad racional } \\
\text { a emocional) }\end{array}$ \\
\hline Aventura & Emocional y simbólico & $\begin{array}{l}\text { Camel / Espíritu aventurero } \\
1988 \text { (reposicionamiento) }\end{array}$ \\
\hline Paraíso & $\begin{array}{l}\text { Iconográfico, simbólico } \\
\text { y emocional }\end{array}$ & Cacharel / Edén 1996 \\
\hline Belleza & $\begin{array}{l}\text { Arquetipo de la belleza } \\
\text { y la sensualidad } \\
\text { (Perséfone) }\end{array}$ & $\begin{array}{l}\text { Christian Dior / J'adore } \\
\text { 2008 }\end{array}$ \\
\hline Hedonismo & $\begin{array}{l}\text { La mujer al servicio del } \\
\text { hombre (Penélope) }\end{array}$ & $\begin{array}{l}\text { Axe (construcción de } \\
\text { marca) }\end{array}$ \\
\hline Carpe Diem & Dionisio (Baco) & Diesel (campañas BTL) \\
\hline $\begin{array}{l}\text { Victoria } \\
\text { Lucha contra } \\
\text { el orden } \\
\text { establecido }\end{array}$ & Diosa Niké (Atenea) & Nike (Just do it) \\
\hline
\end{tabular}

Fuente: elaboración propia.

¿Cuáles son los motivos de esta continua reproducción de los héroes clásicos en el cine y publicidad? Afirmaba Barthes que "todos somos descifradores, creadores y consumidores de mitos", como si de algún modo la sociedad posmoderna necesitase complementar la ausencia de unos valores férreos y unos modelos tradicionales, con una serie modelos en mayor o menor manera ejemplares que encarnan los deseos, las quimeras y los sueños del posmoderno, le evocan lejos de esta realidad a tiempos memorables, a paraísos idílicos, a ideales de belleza y poder, ligados intrínsecamente a respuestas comerciales, a influencia en los factores de consumo.

Es evidente que más allá de la figura del héroe por antonomasia, probablemente representado por Eneas, Perseo, Ulises o Héctor, y a los antihéroes, por sus perfil más libertino, menos virtuoso como sería el ejemplo de Aquiles o Heracles, no son los únicos casos de figuras mitológicas o mitemas que se repiten en la literatura, el cine, la industria musical o incluso los videojuegos, puesto que cabría destacar con fuerza propia el culto por otro tipo de mitos más contemporáneos, como es el caso de los no muertos, sean representados por zombis o bien por vampiros. Estos fenómenos responden a algunas de las características que definen la sociedad posmoderna, como sería la necesidad de unos referentes frente a una cultura materialista. Se trata de unos elementos culturales que aplauden la lucha contra la realidad, con el orden establecido y la búsqueda de continuas vías de escape, de paraísos idílicos que provocan en el hombre la creencia de una realidad fantástica 
El discurso publicitario, del mismo modo que el relato mitológico, se entiende como una narración encriptada, pues si bien posee una vertiente más explícita que suele ir acorde a los elementos más visuales, también posee otra vertiente más encriptada que, en cierto modo, necesita ser decodificada para deshilar los mensajes intrínsecos que posee. Como decíamos, sucede lo mismo con el mito, pues si bien está ordenado a narrar las hazañas y aventuras de unos personajes fantásticos en un tiempo pretérito, también acostumbra a poseer un carácter moralizante, pedagógico y, a la vez, acostumbra a reflejar los apetitos y las pulsaciones de los hombres sobre una realidad ideal (Pérez Tornero, 1992: 81):

La representación publicitaria (...) es eminentemente mítica. La publicidad parece entender que el proceso de consumo es un acto que se da en una realidad contradictoria. Es decir, una realidad ideal y superior a la cotidiana en la que parece que los deseos se vuelvan siempre realidad.

\section{Conclusiones: mitemas y sueños oníricos}

La publicidad, más allá de su estética, composición y discurso, es también una de las industrias más importantes del planeta y, por consiguiente, está reglada y orientada a conseguir sus objetivos de la forma más efectiva posible. Por tanto, los recursos audiovisuales, verbales y semióticos que componen las campañas publicitarias tienen un valor económico y una clara función: poner en contacto al anunciante con el consumidor mediante el lenguaje publicitario y constituirse en un factor determinante en sus decisiones de compra. La publicidad toma del mito componentes alegóricos y simbólicos, conformándose como un compendio retórico suficientemente persuasivo como para influir directa e indirectamente en las tendencias consumistas y provocar ese efecto hedonista y placentero en el consumidor antes y después de la adquisición de los bienes y servicios anunciados. Por otro lado, habiendo subrayado la disyuntiva entre las diferentes interpretaciones del mito y su pertinencia al discurso publicitario y a la sociedad posmoderna que en ellas incurre, es más que factible constatar que el uso del mito como herramienta persuasiva no tiene una función arbitraria ni casuística, sino que se considera deliberada. A su vez, está enfocada por las diferentes estrategias publicitarias en base a los estudios de mercado y a la conocida como psicología del consumidor. También va dirigida, no sólo a persuadir al receptor, conformante de una sociedad eminentemente consumista, sino también a introducirse en su mente. Creando, de esta manera, idearios atractivos, pulsaciones e imaginarios que conforman la imagen de marca, mediante la reiterada reproducción de personajes y valores mitológicos que, desde tiempos inmemorables, forman parte de la cultura y el lenguaje del ser humano.

Sin embargo, la verdadera afirmación concluyente de este artículo es que se ha producido, de forma tan lenta y progresiva que el consumidor ha pasado por alto, la sustitución del mito por la publicidad: los mensajes, promesas, patrones y valores alegóricos que constituyen el discurso publicitario posmoderno han sustituido los 
modelos arquetípicos que la mitología clásica ha legado al sustrato cultural. De este modo, la publicidad en la sociedad consumista posmoderna se ha convertido en el lenguaje de referencia de la cultura actual en un marco hedonista de hiperestimulación visual. La épica, la lírica y el drama han sido substituidos por los nuevos relatos posmodernos caracterizados por un individualismo y un utilitarismo que ha destrozado los modelos y cánones arquetípicos clásicos mediante el mestizaje y fusión de códigos, estilos, tendencias y cánones que potencian la fragmentación cultural donde parezca que todo tenga validez y donde el propio hecho publicitario se convierte en un elemento hedonista y placentero de por sí dentro del enclave consumista en un contexto de hiperestimulación social.

\section{Bibliografía}

\subsection{Libros:}

AAKER, D. (1994). Gestión del Valor de la Marca. Madrid: Díaz de Santos.

ALONSO, J.; GRANDE, I. (2010) Comportamiento del consumidor. Decisiones y estrategia de marketing. Madrid: ESIC.

ALTARRIBA, M. (2003). Del Pregó al Web. Barcelona: Trípodos.

ARROYO, A. (2007). Microrrelatos audiovisuales, publicitarios: la transmisión mítica a través de los sentidos. Madrid: Universidad Complutense de Madrid

BARTHES, R., (1982). La Antigua Retórica. Barcelona: Buenos Aires.

EQUIZÁBAL, R. (2007). De la Publicidad como actividad de producción simbólica. Sevilla: C.S.

GARCÍA GUAL, C. (2001). Diccionario de mitos. Madrid: Siglo Veintiuno de España Editores.

GUSDORF, G. (1990). Mito y Metafisica. Buenos Aires, Argentina: Nova.

JUNG, C. (2002). Los arquetipos y lo inconsciente colectivo. Obra Completa volumen 9/I. Madrid: Trotta.

LEÓN, J.L. (2001). Mitoanálisis de la publicidad. Madrid: Ariel Comunicación.

MARK, M.; PEARSON, C.S. (2001). The Hero and the Outlaw: Building Extraordinary Brands Through the Power of Archetypes. New York: McGraw-Hill.

RAMONET, I. (1983). La golosina visual. Imágenes sobre el consumo. Barcelona: GG.

REEVES, R. (1997). La Realidad en la publicidad. Barcelona: Delvico Bates.

RIES, A.; TROUT, J. (1990). Posicionamiento. Madrid: McGraw-Hill.

ROBERTS, K. (2005). Lovemarks: el futuro más allá de las marcas. Barcelona: Empresa Activa.

VERNANT, J. P. (2000). El Universo, los dioses, los hombres. Barcelona: Anagrama. 